\title{
Seismic Fragility Analysis of Structures Containing Supplemental Damping System
}

\author{
Ashwini P, Steffi Stephen \\ Civil Department, Pillai HOC College of Engineering \& Technology, Rasayani \\ DOI: 10.29322/IJSRP.12.01.2022.p12156 \\ http://dx.doi.org/10.29322/IJSRP.12.01.2022.p12156
}

\begin{abstract}
The structural damage that happens during earthquakes explains the necessity for seismic evaluation, which is used to forecast the potential of structural damage. This paper compares the vulnerability of steel buildings with and without supplemental damping system. Fragility curves are used to describe the degree of vulnerability. Supplemental damping system is a new design and retrofit idea that deals with a well-designed damping system. It is an additional cable damping system that can considerably reduce the risk of damage. A combination of cables, fuse-bars, and dampers are used in the system. Dampers are used to protect buildings from earthquakes. It is proven that the main response would be considerably lessened. The damage will be concentrated on the system while the main structure will remain elastic or with minor inelastic deformation. A well designed fuse bar acts as a sacrificial element which will dissipate seismic energy by inelastic deformation and thus protects the structure by keeping it elastic. Therefore only the fuse can be replaced making the repair works much easier and economical. This methodology is used to design a nine storied steel building and is evaluated using linear and nonlinear analysis. The modeling, linear and nonlinear analysis is carried out using SAP 2000. The seismic performance of building models were analyzed using fragility curves.
\end{abstract}

Index Terms- Fragility Curves, Non Linear Analysis, Structural Fuse, Supplemental Damping System

\section{INTRODUCTION}

An earthquake can be powerful enough to demolish major structures and kill thousands of people. The only technique accessible to ancient architects to prevent seismic devastation was to construct iconic constructions that were abnormally rigid and robust. In earth quake engineering, there are now various design philosophies that use experimental results, computer simulations, and observations from previous earthquakes to provide the requisite performance for the seismic damage. The essential parts of earthquake-resistant structures, particularly their main elements, must be designed with ductility in mind. During an earthquake, such structures can swing back and forth and withstand the effects of the earthquake with significant damage but no collapse.. In addition to the ductile design philosophy another philosophy known as Damage Avoidance Design philosophy has been introduced to withstand major seismic event with minimal and repairable damage.

\section{Supplementary Damping System}

A Supplementary Damping System (SDS) provides extra damping to a structure's natural capacity to regulate motion. An SDS absorbs dynamic energy from a structure and decreases the effects of excessive motion in its most basic form. Structural vibrations can be caused by the wind, people, vehicles, mechanical equipment, and seismic activity. Damping is a low-cost solution to vibration problems. The fundamental principles of vibration apply to all forms of damping systems, despite the fact that there are many different varieties. Structures with asymmetric designs, which are known to be more vulnerable to earthquake damage than symmetric-plan buildings, might benefit from additional dampening. Mechanical devices are built into the building's frame and dissipate energy over the length of the structure. Mild steel yielding, sliding friction, piston motion inside a viscous fluid, fluid orificing, or viscoelastic action in rubber-like materials are all ways for dissipation of energy. Supplemental damping devices dissipate earthquake-induced energy in parallel or in sequence with the main structural system. As a result, energy dissipation demands on main structural elements are lowered (or eliminated), resulting in fewer irreversible deformations and damage to structural and non-structural components.

Benefits:

a) Occupant comfort and safety standards are met.

b) A longer design life (structural durability) is achieved by reducing structural stress and/or fatigue.

c) Costs of construction and upkeep are lower.

d) More space for tenants. 


\section{Structural Fuse Concept}

The structural fuse concept is the idea of using sacrificial elements to dissipate seismic energy while maintaining the integrity of the structure's other key components. Various types of metallic passive energy dissipation (PED) elements can be used to implement the structural fuse concept in new or existing constructions. The proposed approach has various advantages, including cost-effectiveness, a clear load channel, and quick post-earthquake reparability. Through bracing systems, dampers, base isolators, and other methods, the concept has been widely used to constructing buildings in seismically vulnerable areas. Structural fuses assist a building's behavior be more predictable and dissipate seismic energy in the case of an earthquake. The fuse must be extremely ductile in order to withstand the majority of the imposed deformations. A response modification factor is used in seismic design to reduce the load caused by an earthquake, allowing the structure to undergo inelastic deformations. To handle inelastic deformations, this technology relies on the structural parts' stability. Alternative design methods are desirable to achieve high seismic performance standards for buildings. In that case, concentrating damage on disposable and easily repaired structural elements (e.g. structural fuse) would be desirable, while the main structure would be designed to remain elastic or with small in elastic deformations.

\section{Fragility Curves}

Fragility curves are a statistical tool that depicts the probability of exceeding a given damage state (or performance) as a function of an engineering demand parameter that represents ground motion (preferably spectral displacement at a given frequency) or a plot of the computed probability (deflection) vs. Ground motion parameter. Fragility curves have been shown to help predict the severity of probable damage. Fragility is a typical nontechnical description of the attribute of being easily broken or damaged. Kennedy et al. (1980) were the first to apply the phrase "fragility function" in earthquake engineering, defining it as "a probabilistic relationship between component failure frequency and peak ground acceleration in an earthquake." Capacity is determined by the degree of environmental stimulation at which the asset exceeds the undesirable limit state. A fragility function, for example, might be used to define how much shaking a structure can tolerate before collapsing. At a given level of shaking, it has the same risk of collapsing as it has of having less strength than is necessary to resist that level of shaking. The phrases fragility curve and fragility function are occasionally used interchangeably, as are the terms fragility and vulnerability.

\section{LITERATURE REVIEW}

Ramiro Vargas and Michael Bruneau (2009) conduct an experiment on the University of Buffalo's shaking table, in which a threestory structure with buckling restrained bracing on it that act as metallic structural fuses. The usage of seismic isolation devices to safeguard non-structural components is also discussed in the article. It is parametric research that examines the behaviour of nonlinear SDOF systems subjected to synthetic ground vibrations in order to incorporate the structural fuse concept into actual buildings using Buckling-restrained braces (BRBs) as metallic structural fuses. The use of four sets of braces connected to the frame by removable eccentric gusset-plates was also shown to be effective in preventing performance problems seen in other BRB experiments, such as local buckling and out-of-plane buckling of the plates at the connection point. Any final findings concerning the performance of the recommended gusset detail should be dependent on future study because the BRBs were not tested to failure in the frame.

Mohammad Aliaari and Ali M.Memari (2012) provide a design technique for separating frame or infill walls during earthquakes by utilizing a sacrificial structural fuse. The design method is demonstrated using a low-rise and a mid-rise skyscraper. It includes a design and installation method for the fuse system in a multi-bay, multi-story structure with moment resistant frames, as well as an empirical equation for forecasting the in-plane strength of masonry infill walls with structural fuse. The findings indicate that the proposed isolation system has the potential to improve the seismic performance of masonry infill walls by reducing damage to the infill wall and frame as a result of their interaction.

Marco Vona (2014) suggested an analytical fragility curve generation approach for Moment Resisting Frame Reinforced Concrete structures. The selected building typologies were developed utilizing force-based methodologies and the state of the art at the time of construction, in accordance with the applicable codes. In this study, fragility curves are established in light of policy demands for seismic risk reduction at various territorial sizes. Low-engineered, pre-seismic, or post-seismic buildings are among the structures under examination. The most frequent source of fragility curves is post-earthquake or expert data. Unfortunately, owing to an insufficient data, the results might be quite deceptive. As a result, numerical analyses must be employed in conjunction with this strategy.

Sruthi (2014) calculated the fragility of the flat-slab and waffle slab systems. The structural features of the flat-slab system and the waffle slab system, as well as Eigen value and time history studies, were all taken into account while modelling a mid-rise building for this purpose. The flat-slab structure's fragility curves were created and compared to the waffle slab structure's fragility curves. Despite 
the fact that the structural designs and loads were similar, differences were observed. Using the derived fragility curves, the cost of rehabilitation for the structures is then determined.

Objectives of this study are,

- To evaluate the efficiency of supplemental dampening systems and to assess the dependability of structures subjected to seismic loadings.

- To propose a supplementary damping system method based on the DAD design concept.

- To apply the structural fuse idea to accomplish economy. intensities.

- The increase in seismic performance may be assessed by generating fragility curves that relate measurements of earthquake intensity to the chance of surpassing particular performance criteria for the structure.

\section{METHODOLOGY}

The effectiveness of the supplemental cable damping system in minimizing response is made by comparing the responses of the structure with and without supplemental cable dampers for the same earthquake. For that purpose, a building shown in figure 1 is considered. The building is modeled using SAP 2000. The example building is a nine story 2D Steel structure as shown in figure 1 having base dimension of $45.72 \mathrm{~m}$ and a height $40.842 \mathrm{~m}$. The building consists of 5 bays in X direction with each bay $9.144 \mathrm{~m}$. Each floor heights of the building are different with base $3.658 \mathrm{~m}$, first floor with $5.486 \mathrm{~m}$ and other stories with $3.962 \mathrm{~m}$. The $2 \mathrm{D}$ model of the building is shown in figure 2. The specification of the structure is given in Table 1 and specification of materials is given in Table 2 .

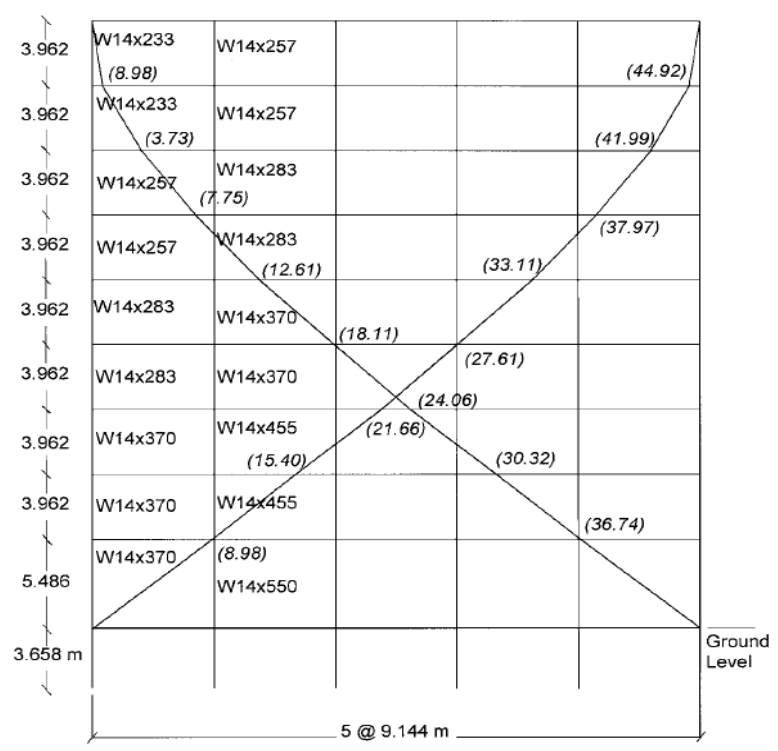

Figure 1: Elevation details of the steel structure

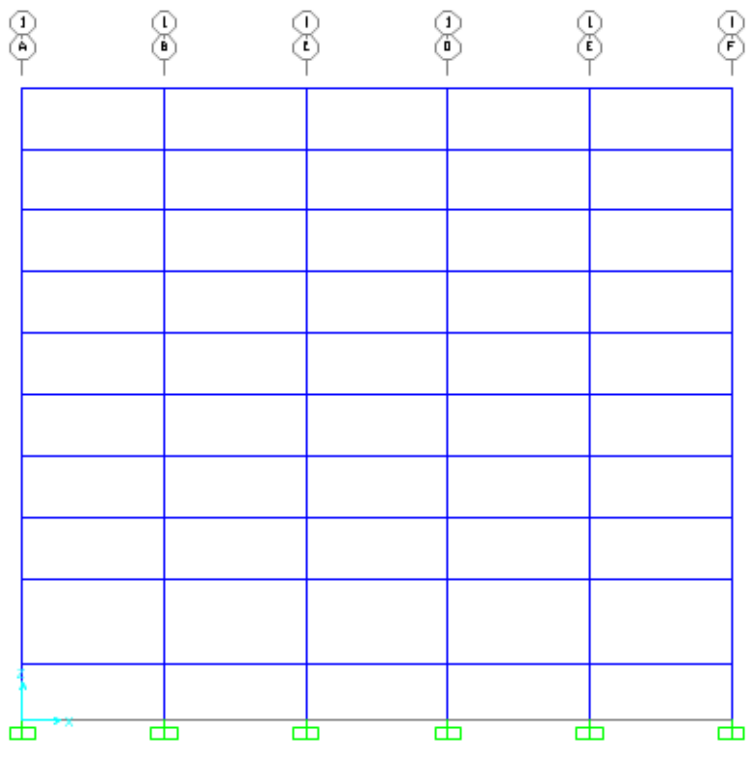

Figure 2: 2D Model of steel structure

Table 1: Specification of the Steel Structure

\begin{tabular}{|l|l|}
\hline Items & Specification \\
\hline Beam material & ${\text { A } 99 F_{\mathrm{y}} 50}^{50}$ \\
\hline Column material & A $99 \mathrm{~F}_{\mathrm{y}} 50$ \\
\hline No of Storey & 9 nos \\
\hline Floor height & $3.658 \mathrm{~m}$ (base), 5.486m (FF), 3.962m(others) \\
\hline Bay width along X direction & $9.144 \mathrm{~m}$ \\
\hline Total building dimension & $45.72 \mathrm{~m} \mathrm{x} \mathrm{40.842} \mathrm{m} \mathrm{ht}$ \\
\hline
\end{tabular}


Table 2: A 99Fy 50 Steel material properties

\begin{tabular}{|l|l|}
\hline Specification & Value \\
\hline Density of steel material & $7849 \mathrm{~kg} / \mathrm{m}^{3}$ \\
\hline Young's modulus of steel material, $\mathrm{E}$ & $199947.48 \mathrm{~N} / \mathrm{mm}^{2}$ \\
\hline Poisson's ratio of steel material, $\gamma$ & 0.3 \\
\hline Shear modulus of steel material, $\mathrm{G}$ & $76903 \mathrm{~N} / \mathrm{mm}^{2}$ \\
\hline Minimum yield Stress of steel material, $\mathrm{F}_{\mathrm{y}}$ & $344.74 \mathrm{~N} / \mathrm{mm}^{2}$ \\
\hline Minimum tensile Stress of steel material, $\mathrm{F}_{\mathrm{u}}$ & $448.16 \mathrm{~N} / \mathrm{mm}^{2}$ \\
\hline Effective yield Stress of steel material, $\mathrm{F}_{\mathrm{ye}}$ & $379.21 \mathrm{~N} / \mathrm{mm}^{2}$ \\
\hline Effective tensile Stress of steel material, $\mathrm{F}_{\mathrm{ue}}$ & $492.97 \mathrm{~N} / \mathrm{mm}^{2}$ \\
\hline
\end{tabular}

Determining cable arrangement for building structures is difficult, especially for tall, flexible buildings and structural frames with strong higher mode effects. If the cable architecture is based on the first mode of vibration characteristics, a higher mode contribution in the overall response could degrade the suggested configuration's performance. However, a cable arrangement can be determined iteratively based on first mode features that have been adjusted to reduce higher mode effects. An estimated supplemental cable damping system is chosen based on the dominant mode shape of the steel structure and is fixed diagonally in an X-Shape in between the frames in the direction opposite to the drift of the building frame; the structure's response is measured. The technique is repeated until the structure's response is greatly reduced by adjusting the supplemental damping parameters, cable profiles, and the number of $\mathrm{X}$-shaped supplemental cable damping systems. Table 3 shows near-optimal cable architecture and supplemental cable dampers parameter. Figure 3 depicts the structure's cable layout.

Table 3: Specification of the supplemental cable damper parameters

\begin{tabular}{|l|l|}
\hline \multicolumn{1}{|c|}{ Items } & Specification \\
\hline Stiffness of Damper $(\mathrm{K})$ & $1926.39 \mathrm{kN} / \mathrm{m}$ \\
\hline Damping Coefficient of Damper C & $3.71 \mathrm{kNs} / \mathrm{m}$ \\
\hline Damping exponent $\alpha$ of Damper & 0.2 \\
\hline Cable & A99Fy-50 \\
\hline 01Cable Diameter & $25 \mathrm{~mm}$ \\
\hline
\end{tabular}

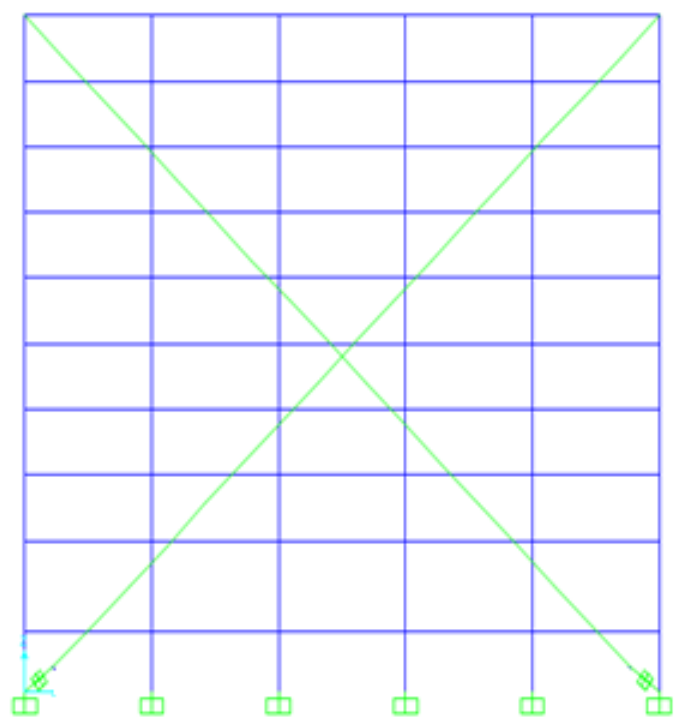

Figure 3: Structure with supplemental cable damping system

Designing structures with supplemental control systems is an iterative process that begins with the design and study of the structure without the supplemental damping system. The amount of additional damping will be determined by the required effective damping 
ratio to accomplish the desired response reduction. Of general, increasing the damping in a structure minimizes the demand forces and deformations caused by earthquakes. The degree of reduction varies depending on the fundamental structure's inherent mass, stiffness, and damping characteristics, as well as the amplitude, frequency content, and duration characteristics of the seismic motion the structure is predicted to undergo. The amount of additional damping will be determined based on these characteristics.

Structural fuse are elements that are easily replaceable designed to protect the primary structure by keeping the main structure elastic or with minor inelastic deformations. They are designed such that all damages are concentrated on the structural fuse which allows the primary structure to remain elastic after a major earthquake. As a result, only the fuse will be replaced, making the repair process easier and more cost-effective. The needed fuse behavior is attained by establishing the hinge property in the fuse element, so that over a threshold magnitude of earthquake, the fuse will give first, keeping the structure and supplemental damping system elastic. As a result, fuse properties and hinge properties can be selected based on the performance goals. Figures 4 depict the supplemental cable damper and structural fuse assembly while figure 5 depict the fuse device's behavior.

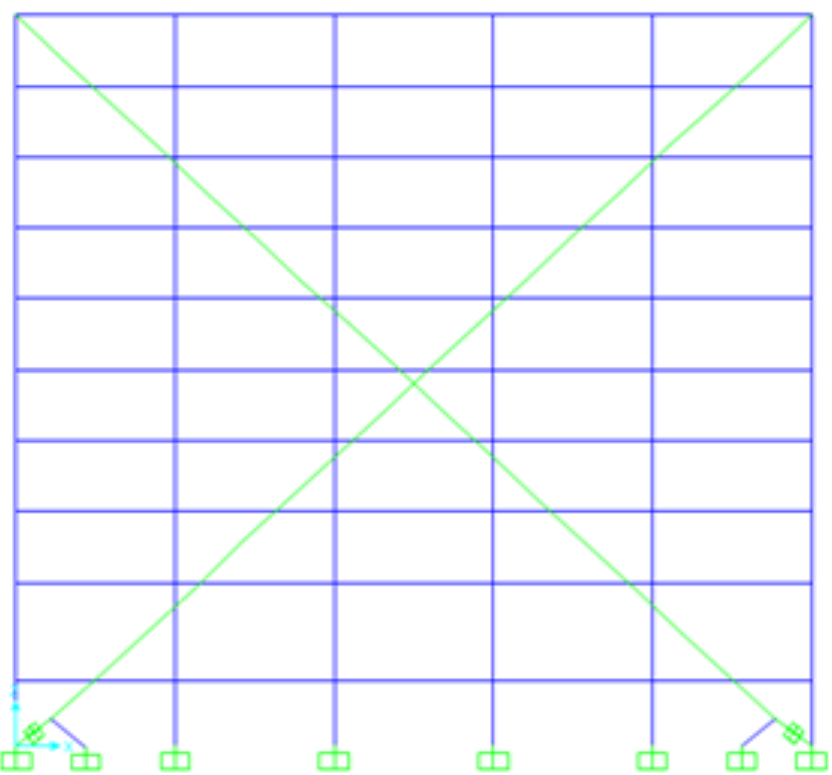

Figure 4: Supplemental cable damper and structural fuse assembly

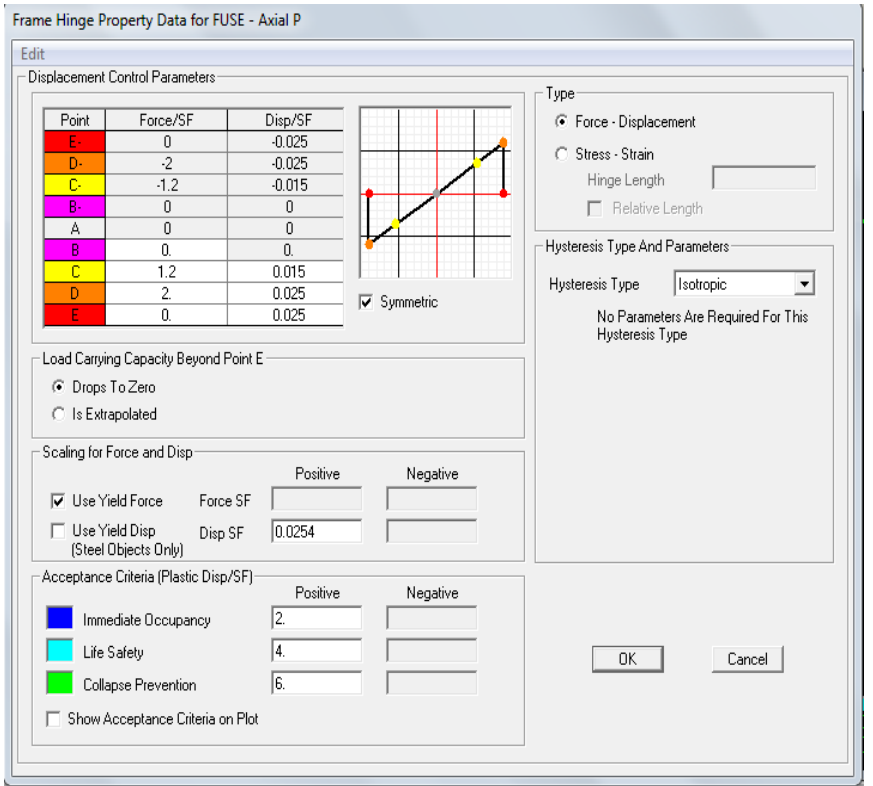

Figure 5: Behaviour of the fuse device

To investigate the response, the structure was subjected to a nonlinear dynamic analysis. The investigation employed time history recordings from the $1940 \mathrm{El}$ Centro earthquake or the 1940 Imperial Valley earthquake (18/05/1940) observed in Imperial Valley in southern California.

\section{RESULTS AND FINDINGS}

From the time history analysis, response for the structure with supplementary damping system and without supplementary damping system is given in table 4.

Table 4: Response for different structural assemblies by Non Linear Time History analysis

\begin{tabular}{|c|c|c|}
\hline Floor Level & $\begin{array}{c}\text { Steel Structure } \\
(\mathrm{mm})\end{array}$ & $\begin{array}{c}\text { Steel structure +Cable damper +Structural fuse } \\
(\mathrm{mm})\end{array}$ \\
\hline Roof & $15.37 \mathrm{~mm}$ & $0.43 \mathrm{~mm}$ \\
\hline $9^{\text {th }}$ Floor & $14.32 \mathrm{~mm}$ & $0.42 \mathrm{~mm}$ \\
\hline $8^{\text {th }}$ Floor & $12.71 \mathrm{~mm}$ & $0.41 \mathrm{~mm}$ \\
\hline $7^{\text {th }}$ Floor & $10.83 \mathrm{~mm}$ & $0.38 \mathrm{~mm}$ \\
\hline $6^{\text {th }}$ Floor & $8.57 \mathrm{~mm}$ & $0.34 \mathrm{~mm}$ \\
\hline $5^{\text {th }}$ Floor & $6.05 \mathrm{~mm}$ & $0.29 \mathrm{~mm}$ \\
\hline $4^{\text {th }}$ Floor & $3.11 \mathrm{~mm}$ & $0.24 \mathrm{~mm}$ \\
\hline $3^{\text {rd }}$ Floor & $1.23 \mathrm{~mm}$ & $0.18 \mathrm{~mm}$ \\
\hline $2^{\text {nd }}$ Floor & $1.05 \mathrm{~mm}$ & $0.11 \mathrm{~mm}$ \\
\hline $1^{\text {st }}$ Floor & $0.73 \mathrm{~mm}$ & $0.02 \mathrm{~mm}$ \\
\hline
\end{tabular}


According to a nonlinear time history study, the lateral displacements were reduced after the supplemental damping system was installed in the structure. Structural fuse bars in parallel with supplemental cable dampening systems can minimize maximum lateral displacement in the structure to (1)/30th to (1)/45th of that of a steel frame structure.

The pushover analysis of a steel structure revealed that the time period (Teff) at the performance point is 0.361 seconds (Figure 6). The structure's overall performance reveals that the first hinge is established between the column support junction and that the structure's performance is within operating limits (Figure 7). The capacity against demand improved significantly in the case of structures with extra cable dampening systems. Figure 8 shows that the performance point time period (Teff) was 0.796 seconds. The accompanying deformation step demonstrates that the structure behaves elastically at the performance point, with no hinge development (Figure 9). As a result, it can be inferred that the supplemental damping systems have significantly enhanced the structure's overall behavior.

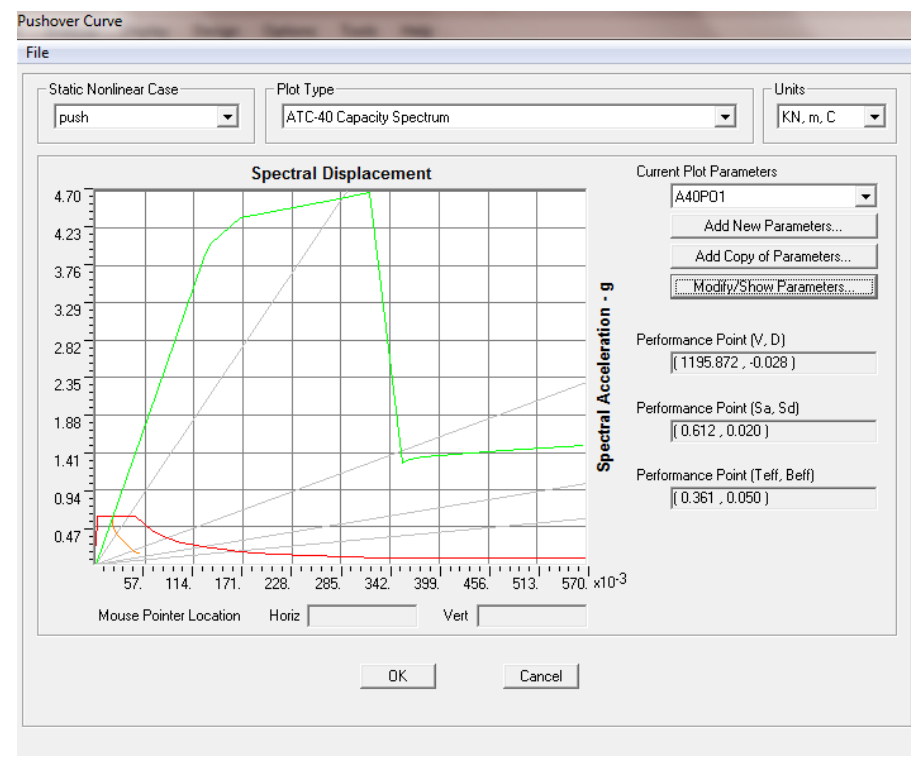

Figure 6: The Capacity demand curve of structure

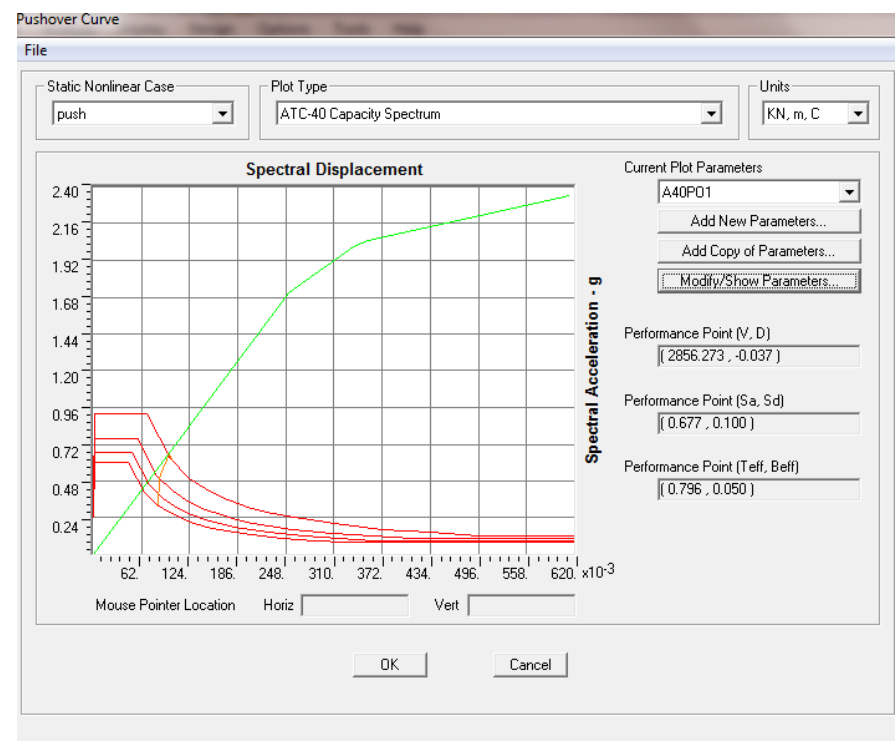

Figure 8: The Capacity demand curves of structure with supplemental dampers
Deformed Shape (push) - Step 3

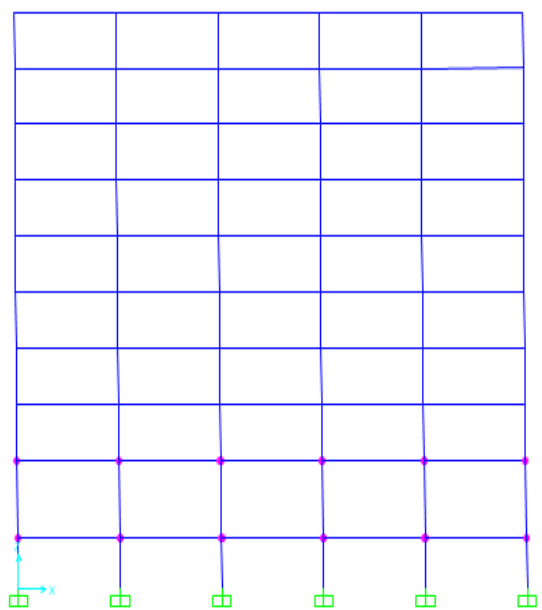

${ }^{\mathrm{E}}$
$\mathrm{C}$
$\mathrm{C}$
$\mathrm{CP}$
$\mathrm{C}$
$\mathrm{CS}$
$\mathrm{B}$

Figure 7: Structure at performance point

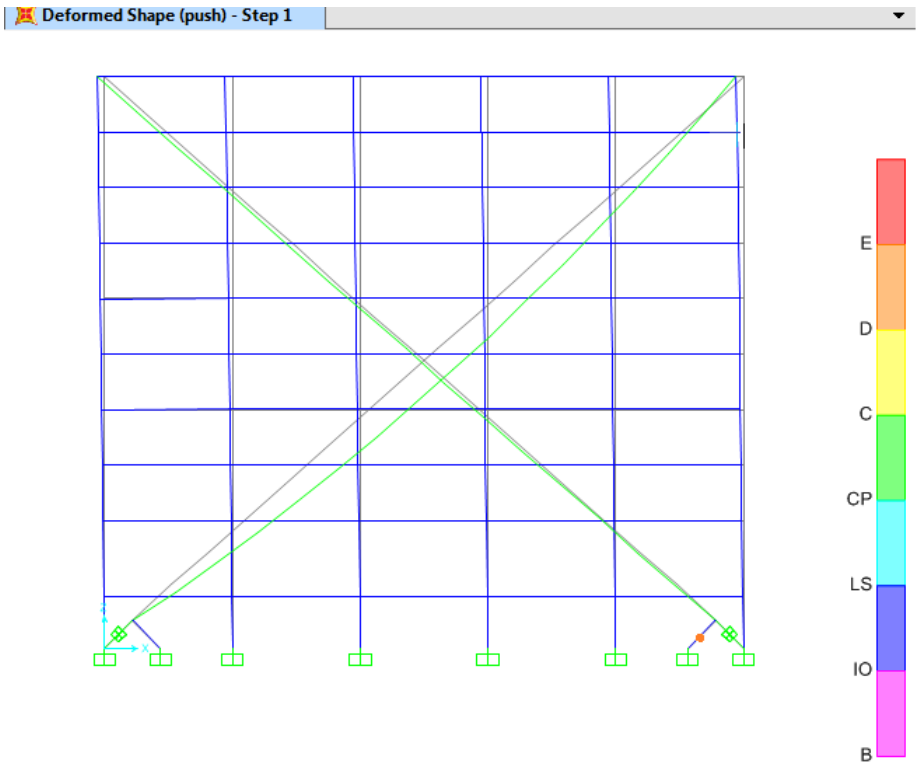

Figure 9: Structure with supplemental dampers at performance point

According to nonlinear pushover analysis, the supplemental damping system has increased the steel structure's capacity, and the structure stays elastic at the performance point with no local failures. As a result, it can be stated that supplemental damping system can significantly improve the structure's overall behaviour. 
The case study building is subjected to 25 earthquake ground motions to demonstrate the methods for deriving the fragility curves. Nonlinear pushover analysis results are used to generate the needed fragility curves for the more severe damage states. The spectral acceleration is the demand parameter in this case. For a particular ground motion, the spectral acceleration (Sa,ds) corresponding to the building's collapse is recorded. Then the median value of demand is determined for 25 ground motion. The dispersion value adopted is 0.4.Then the fragility curve is developed (Figure 10). The fragility curves are developed using FEMA P 58 1. Same procedure was adopted to develop fragility curves for the structure containing supplemental damping system (Figure 11). The value of $\beta$ taken is 0.4 . $\theta$ value for steel structure obtained is $0.172 \mathrm{~g}$ and $1.06 \mathrm{~g}$ for steel structure containing supplemental damping system.

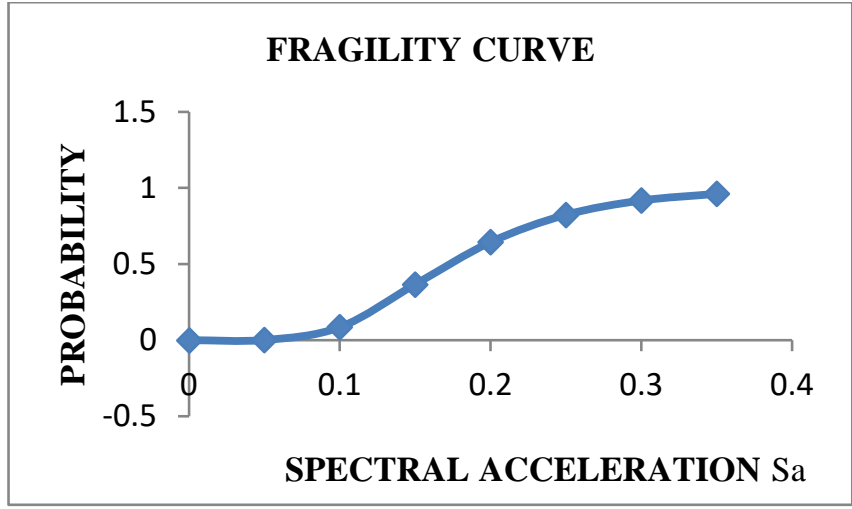

Figure 10: Fragility curve obtained for steel structure

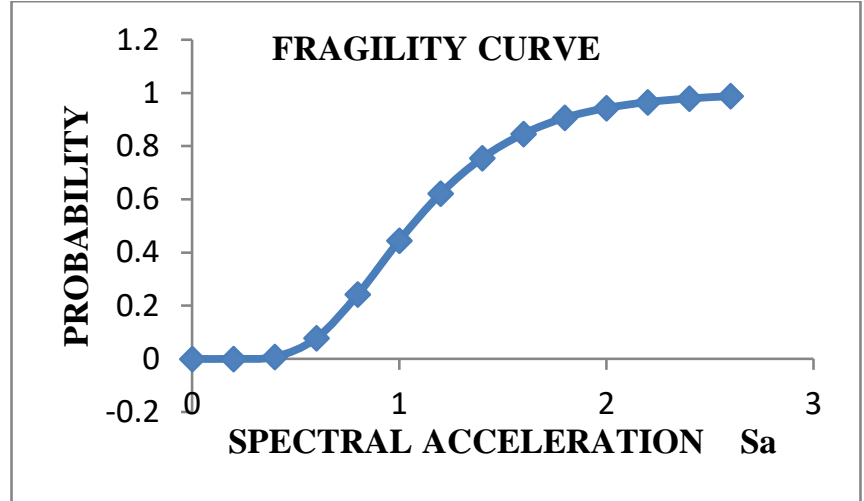

Figure 11: Fragility curve obtained for steel structure containing supplemental damping system

The fragility curves for the two steel structures, with and without supplemental damping system were compared. It was observed that differences exist, even though the structural configurations and the loading were similar.

\section{CONCLUSION}

The following conclusions were obtained:

1. A well-designed supplemental cable damping system can greatly reduce the vulnerability to damage during a seismic event.

2. The maximum lateral displacement of each level was decreased to (1)/30th to (1)/45th of that of a steel frame building using structural fuse bars in parallel with the supplemental cable damping method.

3. Based on nonlinear pushover analysis, the supplemental damping system has increased the steel structure's capacity, and the structure stays elastic at performance point with no local failures.

4. A well-designed Structural fuse bars acts as sacrificial element which will dissipate seismic energy by inelastic deformation and protects the structure by keeping it elastic. Hence only the fuse can be replaced making the repair works easier and economical.

5. It is observed that the fragility curve of steel structures is more vulnerable to seismic hazard than fragility curve of steel structure with supplemental damping system because of the improved performance.

6. Fragility curves derived for both the structure reflect the inherent characteristics of the structure.

7. From the obtained fragility curves, the structure containing supplemental damping system is efficient to seismic prone areas

\section{REFERENCES}

[1] George W. Housner, "The behaviour of inverted pendulum structures during earthquakes", Bulletin of the Seismological Society of America, Vol. 53, No.2, Feb.1963, pp.403-417.

[2] Aslam M, Goddon W.G, and Scalise D.T, "Earthquake rocking response of rigid bodies." Journal of Structural Engineering",ASCE, Vol. 106, No.2, Feb.1980, pp 377- 392.

[3] Priestley M. J. N, and Tao, "Seismic response of precast prestressed concrete frames with partially debonded tendons", PCI Journal, Vol. 38, No. 1, January- February 1993, pp 58-69.

[4] Mander J. B., and Cheng C T, "Seismic resistance of bridge piers based on damaged avoidance design", Technical Report NCEER 1997,Department of Civil and Environmental Engineering, State University of New York at Buffalo.

[5] Gokhan Pekcan ,John B. Mander , and Stuart S.Chen, "Balancing lateral loads using tendon based supplemental damping system", Journal of Structural Engineering, Vol. 126, 2000, pp. 896-905.

[6] Jack J. Ajrab , Gokhan Pekcan, and John B. Mander "Rocking wall-frame structures with supplemental tendon systems", Journal of Structural Engineering, Vol. 130, 2004, pp. 895-903.

[7] R.Vargas and M.Bruneau, "Seismic design of multistory buildings with metallic structural fuses", Proceedings of the 8th US National Conference on Earthquake Engineering, Apr. 2006.

[8] Ramiro Vargas and Michel Bruneau, "Effect of supplemental viscous damping on the seismic response of structural systems with metallic dampers", Journal of Structural Engineering, Vol. 133, 2007, pp. 1434-1444. 
[9] R.E.Vargas and M. Bruneau, "Experimental validation of the structural fuse concept", The14th World Conference on Earthquake Engineering, Oct. 2008.

[10] Ramiro Vargas and Michel Bruneau, "Investigation of structural fuse concept", The14th World Conference on Earthquake Engineering, Oct. 2008

[11] Ramiro Vargas and Michel Bruneau, "Experimental response of building designed with metallic structural fuses II", Journal of Structural Engineering, Vol. 135, 2009, pp. 394-403.

[12] Ramiro Vargas and Michel Bruneau, "Analytical response and design of buildings with metallic structural fuses", Journal of Structural Engineering, Vol. 135, 2009, pp. 386-393.

[13] Mohammad Aliaari and Ali.M.Memar , "Development of a seismic design approach for infill walls equipped with structural fuse", The Open Civil Engineering Journal, Vol. 6, 2012, pp.249-263.

[14] Manoj C.M, "Performance of supplemental cable damping system in mitigating torsional response", Mtech Thesis 2014, Department of Civil Engineering, Saintgits College of Engineering, Kottayam.

[15] A. Singhal and A. Kiremidjian, “ Method for developing motion damage relationships for reinforced concrete frames” Report No.115 1995, Blume Earthquake Engineering Centre, Department of Civil and Environmental Engineering, Stanford University, Stanford.

[16] K. Mosalam, G. Ayala, R. White and C. Roth ,"Seismic fragility of LRC frames with and without masonry infill walls", Journal of Earthquake Engineering,1997,pp. 693-720.

[17] Dumova-Jovanoska "Fragility curves for reinforced concrete structures in Scopje region", Soil Dynamics and Earthquake Engineering ,2000, pp.455-466.

[18] Reinhorn A.M , Barron Corverra R. and Ayala A.G. "Global spectral evaluation of seismic fragility of structures" , Proceedings of the 7th U.S. National Conference on Earthquake Engineering, Boston, 2002.

[19] Masi ,"Seismic vulnerability assessment of gravity load designed RC frames”, Bulletin of Earthquake Engineering , 2003, pp. 371-395.

[20] Wen, Y. K., Ellingwood B. R, Bracci J. "Vulnerability function framework for consequence-based engineering”, Project DS-4 Report 2004, MAE Center.

[21] Kappos, Ch. Panagiotopoulos, G. Panagopoulos and E. Papadopoulos, "Reinforced Concrete Buildings", Risk-UE WP4, 2003. [22] M. A. Erberik and A. S. Elnashai , "Vulnerability analysis of flat slab structures", 13th World Conference on Earthquake Engineering, Vancouver, B.C Canada, paper No.3102, 2004.

[23] S. Akkar, H. Sucuoglu and A. Yakut , "Displacement-based fragility functions for low- and mid-rise ordinary concrete buildings," Earthquake Spectra , Vol.21, No.4, 2005,pp. 901-927.

[24] Mary Beth, Hueste D and Jong Wha,Bai, "Seismic retrofit of a reinforced concrete flat slab structure: Part II- seismic fragility analysis", Engineering Structures, Vol.29, 2007, pp.1178-1188.

[25] M. A. Erberic, "Fragility based assessment of typical mid-rise and low-rise RC buildings in Turkey", Engineering Structures, Vol.30, No.5, 2008, pp. 1360-1374.

[26] B. Ozer AY and M. A. Erberik, "Vulnerability of Turkish low-rise and mid-rise reinforced concrete frame structures", Journal of Earthquake Engineering, Vol.12, 2008, pp.2-11.

[27] Marco Vona , "Fragility curves of existing RC buildings based on specific structural performance levels", Open Journal of Civil Engineering, Vol.4, june 2014,pp 120-134.

[28] Sruthi "Fragility analysis of flat slab and waffle slab structures", M.tech Thesis 2014 , Department of Civil Engineering, Saintgits College of Engineering, Kottayam.

[29] ATC, 1997a."NEHRP Guidelines for the Seismic Rehabilitation of Buildings”, FEMA 273 Report, Applied Technology Council for the Building Seismic Safety Council, Federal Emergency Management Agency, Washington DC.

[30] Alexandra Papailia , "Seismic fragility curves for reinforced concrete buildings", Msc.Thesis 2011, Department of Earthquake Engineering or Engineering Seismology, University of Patras.

[31] FEMA P58 1, "Seismic Performance Assessment of Buildings Volume 1 - Methodology", Applied Technology Council, Sept.2012, Washington D.C.

[32] Martin T. Schultz, Ben P. Gouldby, Jonathan D. Simm, and Johannes L. Wibow, "Beyond the Factor of Safety: Developing Fragility Curves to Characterize System Reliability", Water Resources Infrastructure Program report july 2010, U.S. Army Corps of Engineers Washington DC

\section{AUTHORS}

First Author -Ashwini P, M.Tech in Computer Aided Structural Engineering and currently pursuing Ph.D, Assistant Professor in Pillai HOC College of Engineering \& Technology, Rasayani, Email ID : ashwininairp@gmail.com

Second Author -Steffi Stephen, M.Tech in Computer Aided Structural Engineering, Assistant Professor in Pillai HOC College of Engineering \& Technology, Rasayani, Email ID : steffistephen5492@gmail.com 
Correspondence Author - Ashwini P, M.Tech in Computer Aided Structural Engineering and currently pursuing Ph.D, Assistant Professor in Pillai HOC College of Engineering \& Technology, Rasayani, Email ID : ashwininairp@gmail.com 